\title{
PRECONDITIONS OF APPLICATION OF CALCULATION METHOD ABC IN CUSTOM-MADE INDUSTRIAL PRODUCTION
}

\author{
Andrea SUŠKOVÁ, Jana BUCHTOVÁ \\ VŠB - Technical University of Ostrava, Ostrava, Czech Republic, EU, \\ andrea.suskova@gmail.com, jana.buchtova@vsb.cz
}

https://doi.org/10.37904/metal.2019.974

\begin{abstract}
The paper deals with essential aspects and steps that an enterprise must ensure, within its the organizational structure and the Information systems and technology and manufacturing processes in order to be able to successfully implement the calculation method of Activity Based Costing. The specification of these basic assumptions is mostly part of the input analysis of the costing system of company. The aim of this paper is to focus attention on individual criteria, which may be a pitfall when implementing Activity Based Costing itself.
\end{abstract}

Keywords: Custom-Made Production, calculation method, process, activities, Activity Based Costing

\section{INTRODUCTION}

Due to the growing globalization of the market economy, the importance of custom manufacturing is increasing, especially in industry. The pressure from the competition leads the company to the so-called customization, which often means a change, possibly only partial, in the type of production to order. This entails high demands on production planning and management. These activities both must show synergy with effective cost management [4]. All this must be done in complete flexibility, and above all without undue delay. The manufacturing process must be able to respond quickly to changes in customer requirements, supplier fulfillment and company agility, all in lean manufacturing principles. In practice, all this can be done, provided that optimal calculation methods are set that are able to capture and accept the variability of the production process. The custom-made production process itself has its own specifics. The issues is mainly on the type of production itself, consequently what is the output product. Planning and scheduling the process is complicated by other aspects. These include in particular the number of production batch, concurrent capacity sharing and more. In this paper, custom production means several concurrently producing orders with varying degrees of difficulty. These orders are differentiated in the difficulty of using machine capacities, labor, material consumption, drawing on the consumption of other direct costs and, and the duration of the production of a single contract. For these reasons, it is essential that the default data entering the calculation system is appropriately allocated. Must not be the individual inputs overstatement or underestimation. The diversity of orders can also ultimately result in the application of the Activity Based Costing method being appropriate only for certain activities. In the following points, the Activity Based Costing method (hereinafter referred to as "ABC") and the prerequisites for its application will be briefly presented.

\section{THE CALCULATION METHOD ACTIVITY BASED COSTING}

The basic requirement that led to the emergence of modern costing methods was to allocate costs to performances according to the real causes of costs [1]. If we want to attribute costs to performance by to the real causes of costs, according to the $A B C$ method, we need to define the real causal relationships between performances, internal activities that are necessary realization to performance and the costs that all these activities consume. The ABC calculation returns near the cause-impact relationship. He abandons the traditional assumption that the cause of costs is mainly volume (for example time consumption, material value). At the forefront of $A B C$ calculation is the causal context between the cost and the cost objects. One element enters between these two categories, they are activities. The basic meaning of the $A B C$ calculation is thus to 
express as accurately as possible the relationship of the costs to the cause of their occurrence, especially if the cause the increase the costs is not the final performance increase. From a methodological point of view, it is basically a full cost calculation (the absorption method), which can be combined with the non-absorption method. [2] Figures 1 and 2 show the difference between approach to the costs and their allocation per ABC and often applied the variable cost calculations

The price of products

\begin{tabular}{|l|l|c|c|}
\hline Direct costs & Variable overhead & Fixed overhead & Profit \\
\hline \multicolumn{2}{|c|}{ Variable costs } & $\begin{array}{c}\text { Contribution to fixed costs and profit } \\
\text { generation }\end{array}$ \\
\hline
\end{tabular}

Figure 1 The Cost Structure in Calculation of Variable Costs [5]

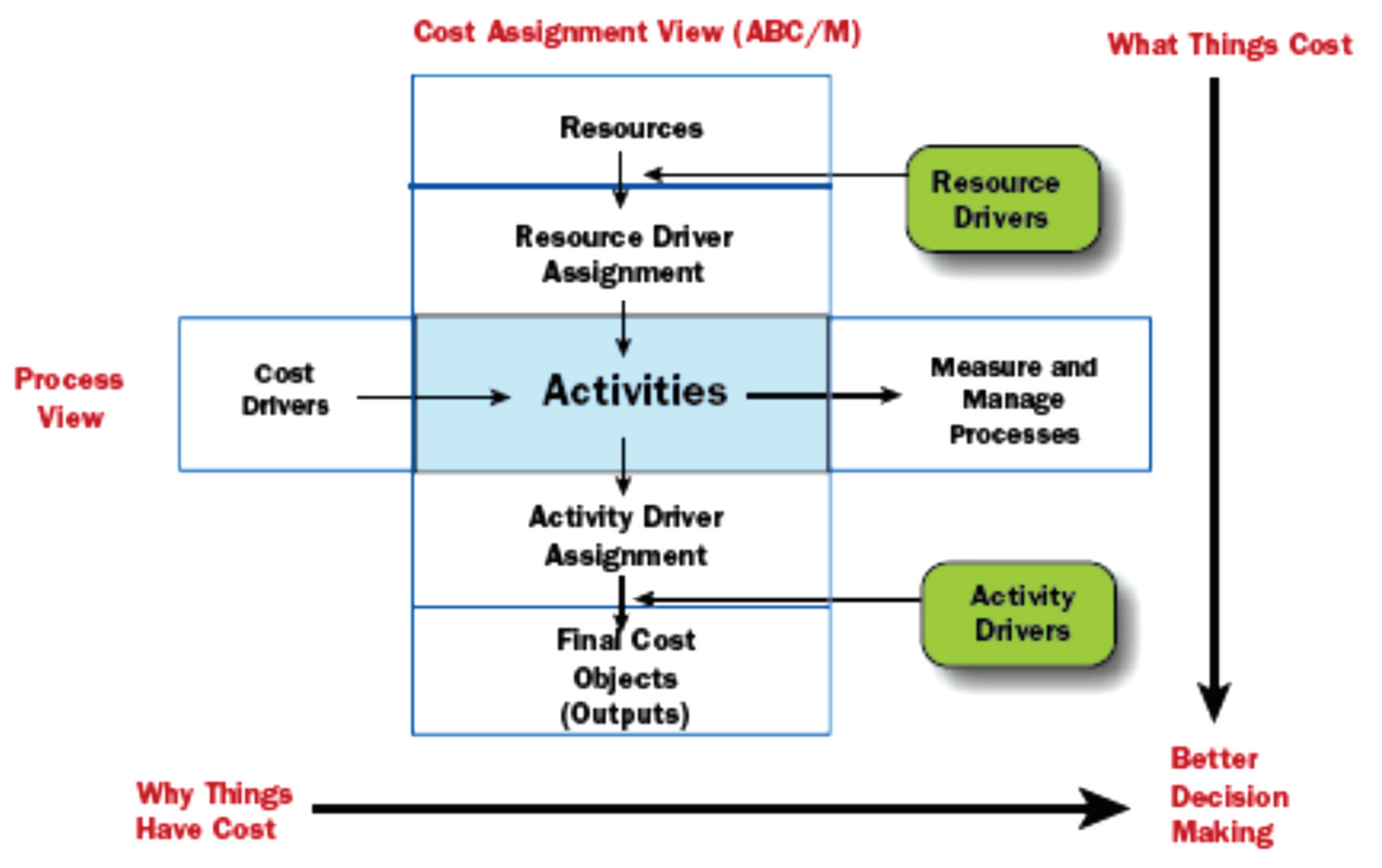

Figure 2 The Activity-based Costing management structure [3]

\subsection{Defining the goals of the $A B C$ method}

It can be seen from the above the figures that assigning the costs to their activities that consume them is not possible without adjusting the default data, the organizational structure, tracking and distributing costs, and adjusting the accounting data.

A lot of benefits are expected from the ABC method. Above all, it will be:

- $\quad$ sufficiently detailed to express reasonably accurate costs;

- $\quad$ reflect the actual course of processes and not just accountability relationships;

- $\quad$ not to track costs only from the point of view of inputs, but also from the point of view of outputs; 
- measure, inter alia, non-economic consumption of costs and lead to the elimination of this phenomenon;

- $\quad$ provide information for decision-making throughout the product life cycle;

- $\quad$ identify processes and expenses that do not add value;

- $\quad$ emphasize planning and cost management itself;

- $\quad$ focus on creating added value and increasing it. [1]

\subsection{Definition of the basic steps of $A B C$ creation}

Given the requirements for report per calculations the $A B C$ method, it is clear that the first step in creating an $A B C$ will be to adjust the accounting data.

\section{a) Adjusting of accounting data}

This first step is based on the principle of differently conception of the costs from the accounting and managerial point of view. First, it is necessary to exclude specific the accounting costs, such as adjustments, certain types of exchange a rate differences, a contractual fees and penalties, a price differences, inventory differences and more. On the other hand, the calculation costs should be identified and subsequently included. These are costs that are not recorded in the accounts, or are recorded in the accounts, but only in accounting terms. These costs include the depreciation of fixed assets in the calculation amount (for example according to the actual life of the asset or without of subsidies received), calculation interest, or other costs related to production processes such as goodwill, development and research costs, advertising and promotion costs, and more.

The next step in creating $A B C$ is

\section{b) Define the structure of the $A B C$}

The basic building blocks of $A B C$ are activities and cost objects. To put it simply, the structure of $A B C$ should be defined not as a copy of the organizational structure, even though it may use their data, but as structure a process of the company. The activities determine the purpose of cost allocation. Therefore, it must correspond with the performance of the company and with the plan of monitored objects within $A B C$. The structure of ABC's activities partly uses some of the company's organizational structure. It is analyzed from the perspective of the purpose of the ABC method. It is necessary to define activities of support, management, development, production, administration and others. These activities are also assigned to the process itself, so that mutual relationships can be defined. After defining the activities, it is necessary to add a precise and unambiguous description of the content of the activity of this activity. Along with this definition of activities, it is also necessary to ensure that the costs that they consume are relevant. Choosing an appropriate or optimal number of activities is a key moment in defining. We understand the cost objects as "the object of consumption of the performance of individual activities". Each cost object consumes a certain amount of activity, expressed in terms of their number of units. [1] In practice, it is often a product, service, specific customer, commodity, order or batch, or other depending on the type of business and its outputs and measured metrics.

\section{c) Assigning the costs to the activities}

The goal of this phase is to identify the amount of costs associated with performing specific activities. The whole process is often called The Process Cost Analysis. The allocation of the costs to activities brings a different view of their effective use, the justification of costs and the cause creation of the cost, as opposed to the standard cost allocation by type. Before assigning costs to activities, it is necessary to divide the costs according to the way they enter the relevant activity. It will be the direct costs that we will set aside for $A B C$ itself. It will also include the costs that can be allocated through activities and the costs that cannot 
be allocated, it is without a causal context with the performance of activities. In practice, this phase is often applied through so-called The Activity cost matrix. [1] The Activity cost matrix then also serves as a backward analysis.

At this stage, we use the cost driver for costs that are summarized in accounting for a particular cost element. Therefore, we need to precisely identify the context to activities and the cause creation of the costs. The most common the cost driver variables include the unit of measurement, the measured performance time, a qualified estimate or a direct classification.

\section{d) Definition of the activities, the cost driver and the costs of activities}

This phase is probably the most extensive in most companies, because it is necessary to determine the activity cost driver, determine the value performance rate of activities, calculate the unit cost of activities, and assign the costs of supporting activities to primary activities. This paper deals with the assumptions and steps preceding the ABC application itself, so we do not discuss this step further in detail.

The last phase of $A B C$ is

\section{e) The Cost allocation of activities to the cost objects}

It is a valuation of the cost objects, which is done by means of the cost driver, which represent the cause creation of how much of a given activity is consumed for a certain cost object. [2] Here too, the same rule applies as in the whole ABC, it is the causal context between costs and activities. Therefore, there is an activity account that defines not only how much a given cost object has consumed units of activity, but also describes the process by which a given cost object passes through the enterprise. This gives us an accurate overview of the total overheads associated with the cost object in question.

It is important to realize that if will be the complexity of the cost objects complicate, the calculation of ABC will be complicate too. However, it is advisable to work with multiple cost objects. The criterion for whether a given cost object to include in the cost system is the effectiveness of that use. [1]

The following part of the paper will be devoted to the basic settings that were necessary in an unnamed company before creating a calculation using the $A B C$ method.

\section{CASE STUDY}

This company produces for custom-made, which is characterized by high variability and changes during the actual realization of the contract. The Sysklass information system is used for the production part, which records individual internal orders from the production plan. The realized production operations and the material consumption are recorded according to the entered BOMs from the technology based on of labor cards. There are a working time records the people and technologies. All data from construction, technology and production are concentrated in this information system. There is also a basic calculation formula, which is the basis for calculating total own costs and recommended selling prices. All this data is transferred to the enterprise-wide information system SAP Business One, where this data is assigned to business orders created by Business Managers based on business contracts.

The first two basic steps taking place at the same time, that means the adjustment of accounting data and the definition the structure of the $A B C$.

The company first proceeded to define the cost objects. There are 12 cost objects, which are further divided into individual centers with a numerical designation. According to the guidelines, all overheads are charged to these individual-cost centers. The cost objects structure is shown in Table 1. 
Table 1 The cost objects structure of the company [own study]

\begin{tabular}{|c|c|c|c|}
\hline Department & Center & Department & Center \\
\hline \multirow{2}{*}{ Company Management } & 1000 & \multirow{29}{*}{ Sales Department } & 1200 \\
\hline & 1050 & & 1201 \\
\hline \multirow{2}{*}{ Economic Department } & 1100 & & 1202 \\
\hline & 1300 & & 1203 \\
\hline \multirow{3}{*}{ Information Technology } & 1400 & & 1204 \\
\hline & 1410 & & 1205 \\
\hline & 1420 & & 1206 \\
\hline Quality Department & 1500 & & 1207 \\
\hline Planning Department & 1600 & & 1208 \\
\hline Controlling & 1700 & & 1209 \\
\hline Human Resources & 1800 & & 1210 \\
\hline \multirow{2}{*}{ Expedition Department } & 2000 & & 1211 \\
\hline & 2100 & & 1212 \\
\hline \multirow{3}{*}{ Purchasing Department } & 3000 & & 1213 \\
\hline & 3100 & & 1214 \\
\hline & 3200 & & 1215 \\
\hline \multirow{3}{*}{ Iechnical Department } & 4000 & & 1216 \\
\hline & 4100 & & 1217 \\
\hline & 5100 & & 1218 \\
\hline Service Department & 5110 & & 1219 \\
\hline \multirow{17}{*}{ Production Department } & 5000 & & 1220 \\
\hline & 5210 & & 1221 \\
\hline & 5220 & & 1222 \\
\hline & 5230 & & 1223 \\
\hline & 5231 & & 1224 \\
\hline & 5240 & & 1225 \\
\hline & 5245 & & 1250 \\
\hline & 5250 & & 1290 \\
\hline & 5260 & & 7000 \\
\hline & 5265 & \multirow{7}{*}{ Operations Department } & 5120 \\
\hline & 5270 & & 6000 \\
\hline & 5275 & & 6100 \\
\hline & 5280 & & 6300 \\
\hline & 5290 & & 6320 \\
\hline & 5295 & & 6400 \\
\hline & 5300 & & 6500 \\
\hline & 5400 & & \\
\hline
\end{tabular}

The accounting records are registered, for example in this form - see Figure 3. The Freight is assigned to both cost center and specific business order or project:

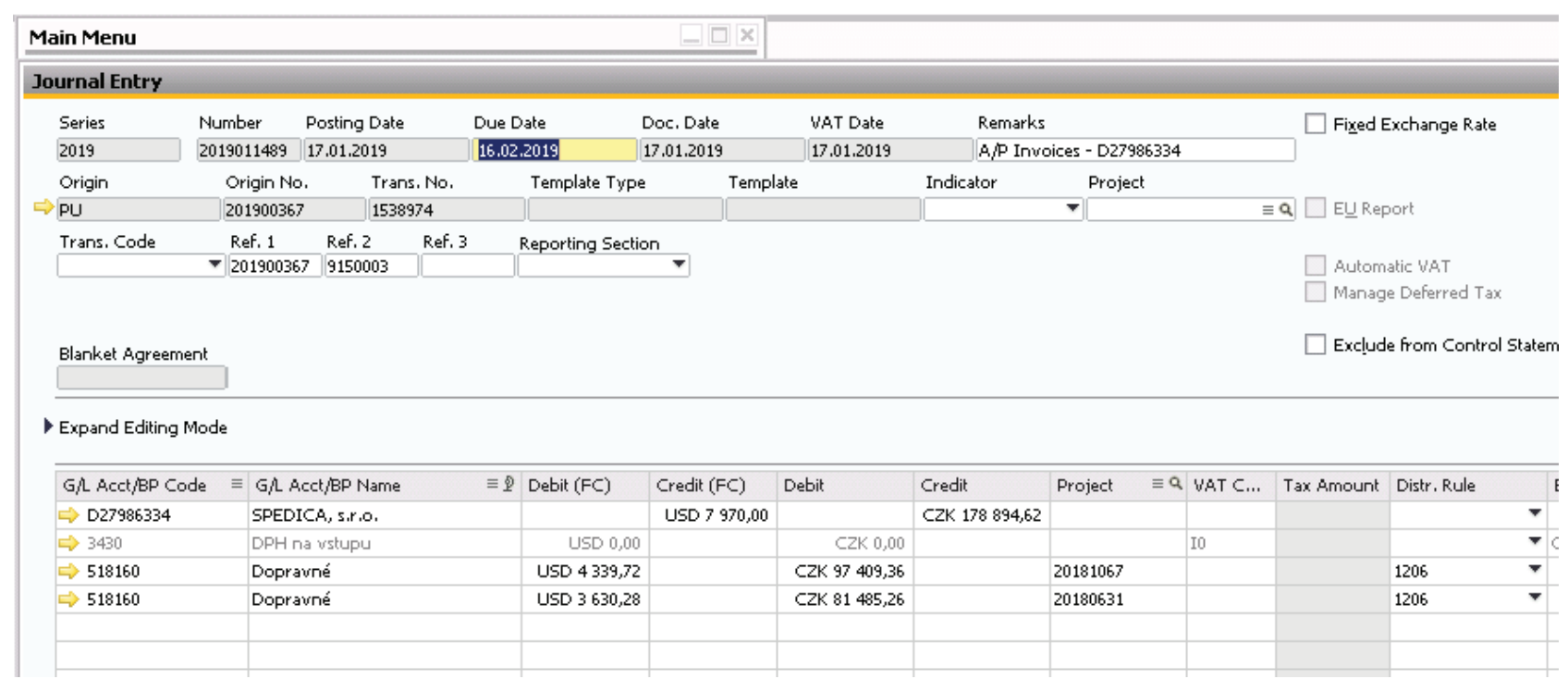

Figure 3 The Accounting Entry of overheads [SAP Business One] 
At the same time, adjustments were made to the accounting data. Costs not related to the main activity of the company were excluded as well as specific costs - adjustments, inventory differences, contractual penalties and exchange rate differences. First step at all, the calculation depreciation was modified, which were determined from the really acquisition prices and based on the optimum possible period of use. The next step was the revision of analytical account 518110 - Other Services, where transactions related to production activities and administrative activities were charged together. Another analytical account 518111 - Other Production Services was created, where only other services related to production activities are newly registered. On account 518110 - Other services, costs related to other administrative services remained.

At the moment, a third phase is under way in the company, this allocating costs to the activities.

Due to the size of the contribution, it is not possible to look in detail at the individual steps of preparing the $A B C$ calculation application, which are very comprehensive and include all the cost objects of the company.

\section{CONCLUSION}

Even though the application of this $A B C$ calculation does not directly affect the performance of the business, it has a benefit in the valuation of individual activities. Practice suggests that traditional methods of calculation in custom-made production are often inefficient and bring disinformation. The $A B C$ calculations provide real data for managerial decisions about capacity, production structure, and more. It reflects the processes, consumption of costs in individual parts of processes and identifies their mutual relationships and bonds. These are the most important outputs of this calculation costing method for cost management in businesses.

\section{ACKNOWLEDGEMENTS}

The work was supported by a specific university research of the Ministry of Education, Youth and Sports of the Czech Republic at VŠB-TU Ostrava No. SP 2019/62.

\section{REFERENCES}

[1] POPESKO, Boris. Moderní metody ř́zení nákladů. Praha: Grada Publishing, 2009. pp.113-128.

[2] MIKOVCOVÁ, Hana. Kalkulace ABC. In: Acta Oeconomica Pragensia, 2008, vol. 16, no. 4, pp. 22-23.

[3] COKINS, Gary. Activity-Based Costing Management: An Executive's Guide [online]. Viley, 2001. pp. 9-14, 374 p. Available from: https://www.researchgate.net/publication/40942624 Activitybased cost management an executive's guide

[4] DUCHOŇ, Bedřich. Inženýrská ekonomika. Praha: Nakladatelství C. H. Beck, 2007. p. 5-12.

[5] KRÁL, Bohumil. Manažerské účetnictví: Studijní text pro kombinovanou formu studia. 2nd ed. Praha: Management Press. 2006, 622 p. 